\title{
USING SIMULATION WITH DESIGN FOR SIX SIGMA IN A SERVER MANUFACTURING ENVIRONMENT
}

\author{
Sreekanth Ramakrishnan \\ Pei-Fang Tsai
}

\author{
Dept. of Systems Science and Industrial \\ Engineering \\ Binghamton University \\ P.O. Box 6000 \\ Binghamton, NY 13902, USA
}

Christiana M. Drayer

\author{
2455 South Road \\ Integrated Supply Chain \\ IBM Corporation \\ Poughkeepsie, NY 12601, USA
}

\author{
Krishnaswami Srihari \\ Dept. of Systems Science and Industrial \\ Engineering \\ Binghamton University \\ P.O. Box 6000 \\ Binghamton, NY 13902, USA
}

\begin{abstract}
This research presents an integrated simulation modelingDesign For Six Sigma (DFSS) framework to study the design and process issues in a server manufacturing environment. The server assembly process is characterized by long cycle times, high fall-out rates and extremely complex assembly operations. To ensure on-time customer delivery, these enterprises adopt a make-to-plan and build-to-order philosophy. However, this model is extremely complex, resulting in wastes and inefficiencies in the associated processes. Lean and six sigma approaches have been successful in improving performance by eliminating waste in the design and operational processes. In this study, an integrated simulation modeling - DFSS framework is proposed to (i) address effects of variation, (ii) assess interactions effects between various sub-systems, and (iii) study proposed process (or design) changes, while performing "what-if" analysis. This framework was then used to identify opportunities for improving the operational and design issues in a server manufacturing environment.
\end{abstract}

\section{INTRODUCTION}

Server manufacturing is characterized by high customer expectations, short turnaround times, wide variety of product base and long manufacturing cycle times, contributing to considerable supply chain complexities (Cheng et al. 2005). Moreover, it also has unpredictable demand, coupled by high fall-out rates and high capital investments. Hence, these organizations have a significant challenge in balancing the operational efficiency (capacity, workload and resource utilizations), while being responsive to customer demands.

The fabrication-fulfillment model is employed by the server manufacturing environment for its operational processes. During the fabrication phase, the various components are procured, tested and assembled into subassemblies, based on pre-defined build plans. These tested sub-assemblies are then stocked for the final assembly. In the fulfillment phase, the tested sub-assemblies are assembled based on the customer order configuration. Once the customization is complete, the servers are shipped to the customers, thereby eliminating any finished goods inventory. Hence, the fabrication-fulfillment model provides the server manufacturing organizations with the flexibility of mass customization and the speed and efficiency of mass production (Chen et al. 2006, Cao et al. 2003, Drayer et al. 2008).

The servers manufactured are expected to function at extremely high levels of reliability, with limited to no downtimes. Hence, the testing of the components and the sub-assemblies are extremely intense and are expected to identify any potential failure modes before it reaches the customer. Failures can occur at any phase of the product development life cycle - research, development, production and customer locations (Luce et al. 2005). The sixsigma initiatives typically focus on identifying defects in the production and customer delivery phases, wherein the defects are easily identified but are extremely costly to fix. However, the Design for Six Sigma (DFSS) techniques are better suited for identifying the various failure modes during the earlier phases of the product life cycle, where defects are harder to predict, but less expensive to rectify.

Hence, one of the key challenges in the server manufacturing process is the high fall-out rates, translating into low first pass yields (FPY). Additionally, the high fall-out rates are attributed to the product complexity and constant design changes. The low FPY often result in (i) increased capacity requirements, (ii) additional resource requirements, (iii) increased scrap costs and (iv) longer cycle times. These pose a substantial risk to on-time delivery of these servers to the customers. DFSS techniques and other lean concepts are employed to identify opportunities for improvement in the design of both the product and the process. These techniques include process mapping, whereas quality function deployment (QFD), failure mode 


\section{Ramakrishnan, Drayer, Tsai, and Srihari}

effects and analysis (FMEA) and fault tree analysis (FTA) are typically used for product designs.

In the recent years, lean and six sigma concepts have become the standard approach to resolve both the design and operational issues in manufacturing and other domains (Standridge and Marvel 2006). While lean concepts attempt to reduce the sources of wastes in the process, the six sigma techniques enable process improvement initiatives. Six sigma is a customer-focused problem solving technique that utilizes powerful statistical tools (Ferrin et al. 2005).

However, there are limitations associated with using these techniques. Most of lean and DFSS techniques study static and deterministic models, which lack the dynamic variability in the process. Standridge and Marvel (2006) present a detailed discussion on "why lean needs simulation". The authors argue that for maintaining an efficient operational process and for producing defect-free products, lean and DFSS techniques may fall short in (i) accounting for variability and randomness in the process, (ii) interactions between the various sub-systems, (iii) studying alternatives and perform "what-if" analysis and (iv) quantifying the various performance metrics to make informed decisions prior to implementation.

Discrete event simulation has been proven valuable as a practical tool for representing complex interdependencies, evaluating alternative designs and policies, and analyzing "what-if" scenarios for systems such as the server manufacturing process (Chen et al. 2006). In a domain such as server manufacturing, there are numerous processes and functions that interact with each other making it imperative to account for them while making any decisions. Since the traditional approaches and spreadsheetbased models are incapable of accounting for these factors simultaneously (Drayer et al. 2008, Chen et al. 2006), a simulation-based approach is desirable for a robust decision support system (DSS) to make informed decisions based on both processes and product attributes.

There have been numerous publications focusing on integrating lean, six sigma and DFSS methodologies with simulation modeling (Luce et al. 2005, Standridge and Marvel 2006, Ferrin et al. 2005, Zee and Slomp 2005, Rivera and Marovich 2001). Eldabi and Young (2007) present the application of discrete event simulation and Plando-check-act (PDCA) cycle in healthcare applications. They mention the importance of simulation modeling techniques to represent the variation in the processes in healthcare delivery systems.

However, these attempts were focused primarily on service providers, such as hospitals and call-centers, with fewer approaches in the manufacturing domain. There are a few research attempts to use an integrated DFSS - simulation modeling approach to enable decision support in complex manufacturing operations. Some of the relevant approaches are listed in the next section.

\section{REVIEW OF RELEVANT LITERATURE}

Mead et al. (2006) present an approach using simulation modeling and costing techniques to represent a production operation and inventory tracking system. This research linked the multi-period simulation modeling with MRP systems and presented methods to calculate costs accrued in manufacturing processes. However, this research fails to address the relationship between design costs and the manufacturing costs. Revetria and Tonelli (2007) and Kuhn (2006) present a quasi 'black-box' simulation model which integrates the design of experiments (DOE) within the industrial simulation.

There are also research attempts which present the application of simulation modeling techniques in the server manufacturing area. Chen et al. (2006) present the application of simulation to model the complex processes associated with server manufacturing. Benjavar and ElHafsi (2006) present a model for determining an 'optimal' production and inventory control model for an assemble-toorder (ATO) enterprise using Markov decision process coupled with simulation modeling. Cao et al. (2003) present a simulation-based inventory management tool designed to visualize Days of Supply (DOS) levels for current and projected demands in a server manufacturing environment. However, these approaches do not address the impact of variations in the product design phase on the operational processes.

Based on the literature review, this research is unique in the following ways:

a. Use of simulation modeling in a server assembly environment: The existing approaches focus primarily on inventory modeling with limited insight into the operational processes and product design (Chen et al. 2006, Cao et al. 2003). This research uses discrete event simulation models for studying the operational processes and its interaction with the product design in a server assembly area.

b. Integration of different DFSS techniques with simulation modeling: In this research, DFSS techniques (QFD and FMEA) are used in tandem with simulation modeling for improved decision making. The DFSS techniques will be used primarily to study the design issues in the product, whereas the simulation modeling is used for operational management.

c. Design of control mechanism: By continuously monitoring any performance measure (first pass yield, cycle time), the simulation models can be used for negating any 'out-of-control' situations, such as a production disturbance. This is another unique feature of this research. 


\section{RESEARCH OBJECTIVES}

Server manufacturing is an extremely complex process with expensive sub-assemblies and long cycle times. Hence, it is critical to develop the testing process to capture any defects before the servers are delivered to the customers. The result of extensive testing translates into high fall-out rates (or low values of FPY). This also leads to more capacity and resource requirements, while resulting in high scrap costs. Oftentimes, it has been observed that many factors that have greater impact on FPY can be traced back to the product design. Hence, it is imperative to use lean and DFSS techniques in studying the operational process and the product design, simultaneously. This is extremely critical while introducing new products or processes.

In this research, we propose a thorough framework using various DFSS techniques along with simulation modeling for providing decision support in a fabricationfulfillment environment. The simulation models are extremely data-intensive and are linked with the shop-floor control systems for real-time data access and/or for continuous updates to the model's statistical distributions. Through this framework, inputs from the DFSS techniques, such as QFD, FMEA and FTA can be fed to the simulation models for studying the impact of any changes identified by the lean/DFSS teams. This framework, thereby ensures that the impact of both product and process changes can be studied prior to decision making. The following are the key research objectives:

1. Integrate product design techniques such as QFD and FMEA with simulation models to serve as a test-bed for "what-if" analysis of both process and product design changes.

2. Provide a technique to estimate manufacturing value added cost in the server manufacturing environment, along with a methodology to determine the energy costs.

3. Develop a procedure which can continuously monitor and check for 'out-of-control' situations in the operational processes.

\section{METHODOLOGY}

The methodology followed in this research is discussed in this section.

a. Study the fabrication-fulfillment model and its application in the server manufacturing process;

b. Develop the baseline simulation model which accurately reflects the process in the server manufacturing area;

c. Integrate the DFSS techniques with the simulation models and develop and study the "what-if" scenarios;

d. Provide results from the simulation runs to the decision makers through a decision support system; and e. Develop a continuous monitoring system to detect any product or process design changes.

The process flow of the fulfillment operations in a server manufacturing process is shown in Figure 1 below. The study presented in this paper focuses only on the fulfillment operations, since the process is based on the customer requirements and any failures detected during the fulfillment test operations has implications on the delivery times and promised due dates. However, it has to be noted here that the framework presented in this research can be applied to the fabrication process as well.

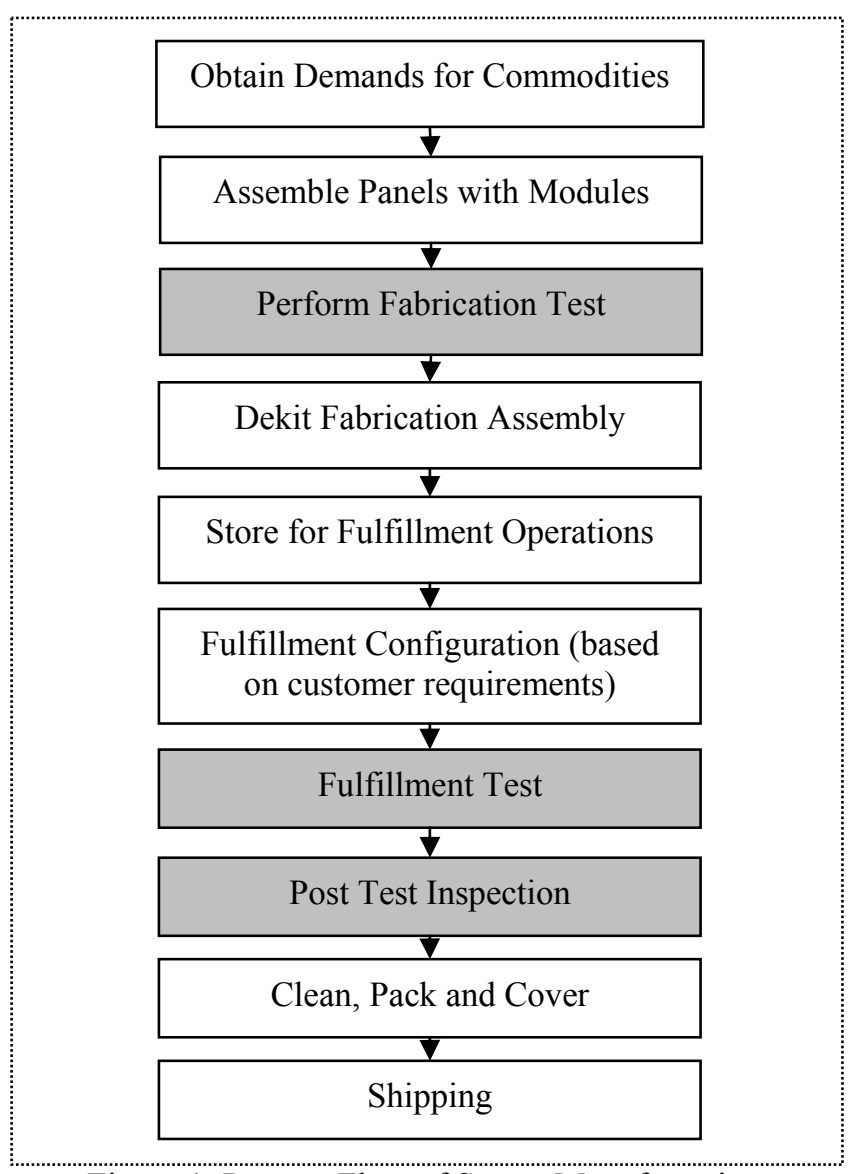

Figure 1: Process Flow of Server Manufacturing

As mentioned in the previous sections, these servers need to perform at high levels of reliability with limited to no downtimes at the customer locations. While process mapping was being conducted, the key bottlenecks were also identified (shown by the gray cells in Figure 1).

It was also observed that the constant engineering changes and product handling had an impact on the yields observed in the test processes, resulting in extremely long test cycle times and rework/repair cycles, additional capacity and workload requirements and increased scrap costs. Moreover, it was evident that the design changes in the product were not effectively reflected on the operational process. This framework proposed in this research will 
combine simulation modeling with DFSS techniques such as QFD, FMEA, and FTA to study the impact of various design changes in the product and the operational process.

\section{DEVELOPMENT OF THE FRAMEWORK}

In this section, the architecture of the framework and its functionalities are presented. Table 1 presents the stages in a DFSS study and the role of simulation modeling in the framework proposed in this research. The five stages in a DFSS study, include Define, Measure, Analyze, Improve and Control (DMAIC).

Table 1: DMAIC Phases and the Role of Simulation

\begin{tabular}{|l|ll|}
\hline Define & $\bullet$ & Understand the process and its context \\
& $\bullet$ & Identify key metrics and processes \\
\hline Measure & $\bullet$ & Perform process mapping \\
& $\bullet$ & $\begin{array}{l}\text { Collect relevant data and perform statis- } \\
\text { tical analysis }\end{array}$ \\
\hline Analyze & $\bullet$ & $\begin{array}{l}\text { Pareto Analysis to identify main defect } \\
\text { categories and assign root causes }\end{array}$ \\
& $\bullet \begin{array}{l}\text { Quality Function Deployment and Fail- } \\
\text { ure Mode Effect and Analysis }\end{array}$ \\
& $\bullet \begin{array}{l}\text { Conduct designed experiments } \\
\text { Integration with Simulation Modeling } \\
\text { to quantify impact of any proposed } \\
\text { changes to the process or product de- } \\
\text { sign }\end{array}$ \\
\hline Improve & $\bullet \begin{array}{l}\text { Identify solutions for implementation } \\
\text { Process capability analysis }\end{array}$ \\
\hline Control & $\bullet \begin{array}{l}\text { Ensure continuous monitoring } \\
\text { Develop management system to moni- } \\
\text { tor changes in process or product design } \\
\text { (through control charts) }\end{array}$ \\
& \multicolumn{2}{|l}{} \\
\hline
\end{tabular}

\subsection{Define, Measure and Analyze Phases}

The 'Define' and 'Measure' phases have been used effectively to develop the baseline simulation model (Section 6 has more details) and also to determine the various contributors to the production disturbance. The disturbance could be capacity issues, machine failures, low yields or resource unavailability. In the 'Analyze' phase, the factors that impact to the production disturbance were determined using the DFSS techniques.

QFD and FMEA can be used to identify solutions to 'neutralize' the production disturbance in the server manufacturing process. From these analyses, the design team can study the corrective actions and make any design changes to the product. However, these design changes should be made only after studying the impact of these changes could have on the operational process. The simulation modeling technique is extremely useful in this situation.
The DFSS techniques are mostly deterministic in nature and do not account for the inherent randomness in the processes. Once the design alternatives are identified (via the QFD and FMEA), yield models and unit hour models need to be modified to reflect these changes. The yield and unit hour models help to translate the product design changes to a related metric (or metrics) in the operational process. For example, the Risk Priority Number (RPN) calculated in the FMEA can be used effectively to feed information to the yield models to predict the yields in the process as a result of design changes. There are other attributes which can be used to determine the changes to the yields or unit hours. Some of them include, defects per million opportunities (DPMO), product type and product complexity. The details of the yield and unit hour models will be discussed in a subsequent publication.

Once the models are updated, the simulation models representing the operational processes are initiated, only when a statistically significant change is observed. The process team can then perform "what-if" scenarios with the simulation models to study the impact of these yield changes. Designed experiments and Analysis of Variance (ANOVA) are conducted to study the responses by altering the factors and determining its statistical validity respectively. Figure 2 shows the overall structure of this framework.

\subsection{Improve and Control Phases}

In the 'Improve' phase, the results from the designed experiments and the simulation models are studied. The teams can study the impact of any product design change on the overall fulfillment process by comparing the overall design costs and the MVA costs as a result of the design changes. Subsequently, the decisions pertaining to the design and process change could be made.

In the 'Control' phase, the FPY was continually monitored for any trends or 'out-of-control' situations. Moreover, the impact of the design changes is carefully tracked and fed back to the FMEA for subsequent analysis. When the FPY was observed to be 'out-of-control', the following actions were triggered:

1. The simulation model is updated with the current FPY and different scenarios are run to negate the production disturbance, by changing the required number of test cells, headcount and dispatching rules in each scenario.

2. Initiate the DFSS process and determine the root cause of the 'out-of-control' situation. Perform process FMEA to identify the causes.

3. If the failure mode is recognized as a design issue, then the design team is involved for further analysis (QFD and FMEA). 
4. Once the QFD and FMEA is conducted, "what-if" scenarios for product design changes are conducted to estimate its impact on the fulfillment process.

5. Make any appropriate process or design changes and continuously monitor for any 'disturbances'.

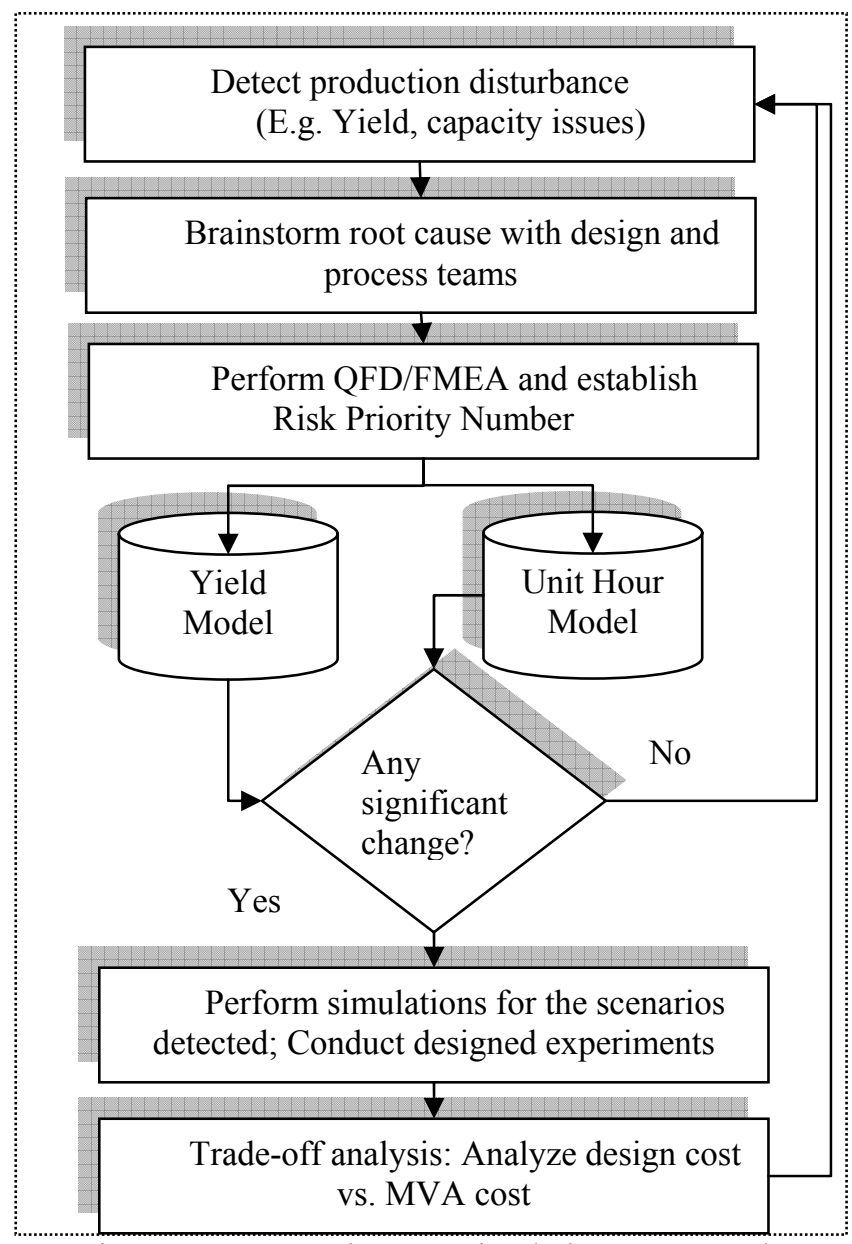

Figure 2: Integrated DFSS-Simulation Framework

\section{SIMULATION MODEL DEVELOPMENT}

\subsection{Data Collection, Process Mapping}

In this stage, the goal was to obtain credible data for building the simulation models, while identifying the key stages in the server manufacturing process. The trusted data sources for the various processes shown in Figure 1 were identified and the data collected for a period of a year. In a server manufacturing environment, the demands are skewed across a quarter, with the first month with the least number of orders and the third month with the maximum number of orders.

The granularity of the data collected was chosen carefully to accurately reflect these characteristics. Time studies were also conducted to validate the information re- trieved from the trusted data sources. Some of the distributions obtained based on the data collected are summarized in Table 2.

\subsection{Assumptions for Model Development}

The following assumptions were made during the development of the simulation model:

- Scope limited to the fulfillment process only.

- Manufacturing value-added (MVA) costs that include workload, capacity and scrap, were considered for the analysis.

- Transportation times were embedded in the statistical distributions of the succeeding operation.

- Cost of lost revenue, due to missed customer order shipments, were not considered in the analysis.

- All DFSS-related inputs were fed through the an excel-based interface to the simulation models.

- All results were reported at a confidence level of $95 \%$.

Table 2: Statistical Distributions (Illustration)

\begin{tabular}{|l|l|}
\hline Process & Distribution \\
\hline Order arrival rate & $-0.001+\mathrm{EXPO}(0.353)$ per day \\
\hline Entities per arrival & $\mathrm{BETA}(28.3,12.2)$ \\
\hline $\begin{array}{l}\text { Number of memory, } \\
\text { nodes }\end{array}$ & $\begin{array}{l}-0.5+85 * \mathrm{BETA}(0.56,0.247), \\
\mathrm{NORM}(352,155)\end{array}$ \\
\hline Test cycle time & $(-1+\operatorname{LOGN}(3.28,1.45))$ hours \\
\hline Order cancellations & TRIA $(0.1,0.24,0.3)$ \\
\hline
\end{tabular}

\subsection{Model Development}

The simulation model was built using Arena ${ }^{\circledR} 11.0$ to accommodate three product types. Table 3 shows the characteristics of the simulation model. One of the key challenges of developing the baseline model was implementing the complex logic to accurately represent the fabricationfulfillment process in a server manufacturing environment. As in any simulation study, it is critical to ensure the model has the appropriate level of granularity and modularization. Figure 3 shows the logic of the simulation model, with its relation to the fabrication process.

As shown in Figure 3, the process has numerous locations where there are complex interactions and involve levels of uncertainty. Implementing the order configuration based on customer requirements was addressed effectively using Arena's 'Hold and Signal' modules, whereas the 'Batch and Separate' modules were used during the test and repair processes of each customer order.

Figure 4 shows the implementation of configuring a customer order through the 'Hold and Signal' module. The customer order is configured only when both commodities 
are readily available. So, one of the commodities is placed in the Hold module and is released only when the other commodity releases a signal. Subsequently, these entities are combined through a Batch module, thereby creating a new entity.

Another key consideration during model development was the handling of the rework or repair actions during fulfillment test. As discussed below, there were three different locations where the defects could be detected. Each defect could have varying degrees of severity associated with it.

Table 3: Simulation Model Characteristics

\begin{tabular}{|c|c|}
\hline Entity & Customer Order \\
\hline System Type & Steady State; Terminating \\
\hline Attributes & $\begin{array}{l}\text { Product type } \\
\text { Alterations/cancellation flag } \\
\text { Energy consumption rate }\end{array}$ \\
\hline Resources & $\begin{array}{l}\text { Assembly stations and operators } \\
\text { Test cells and operators } \\
\text { Rework stations and operators } \\
\text { Shipping stations and operators }\end{array}$ \\
\hline Inputs & $\begin{array}{l}\text { Arrival times of orders } \\
\text { Number of memory cards } \\
\text { Number of nodes } \\
\text { Number of I/O cards } \\
\text { Energy consumption rate } \\
\text { Process times at operations } \\
\text { First pass yields }\end{array}$ \\
\hline Outputs & $\begin{array}{l}\text { Throughput } \\
\text { Cycle times } \\
\text { Resource utilizations } \\
\text { Energy costs }\end{array}$ \\
\hline $\begin{array}{l}\text { Replication } \\
\text { Length }\end{array}$ & 80 Days \\
\hline $\begin{array}{l}\text { Number of Repli- } \\
\text { cations }\end{array}$ & 25 \\
\hline Hours Per Day & 16 \\
\hline
\end{tabular}

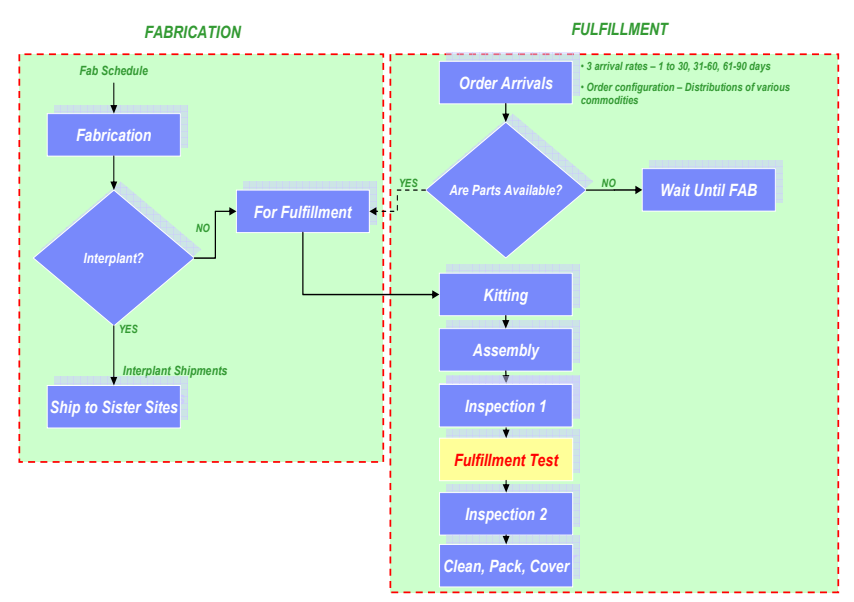

Figure 3: Simulation Model Logic
However, through the integrated DFSS-simulation modeling framework, the severity rating associated with any failure mode in the FMEA could be translated for use in the simulation model.

1. Detection of failures at 'Inspection 1': When defects are detected during this pre-test inspection, the server was sent back to the assembly process, wherein any defects could be isolated and repaired. Based on historical data, the various defect categories and the probability of occurrence were also estimated. It was also observed that it takes an additional $15 \%$ processing time to repair the defects detected.

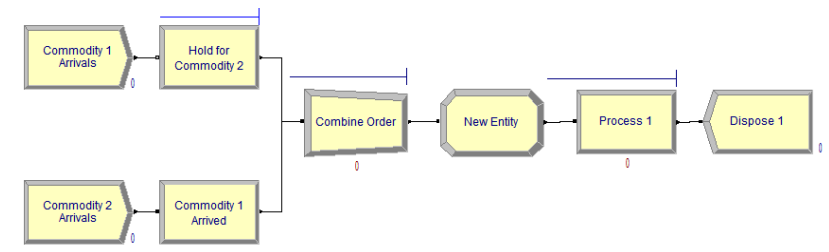

Figure 4: Implementation of Order Configuration

2. Detection of failures during 'Fulfillment Test': Based on the QFD and FMEA's conducted earlier, approximately $80 \%$ of the defects could be repaired in the fulfillment test operation itself. However, once it was repaired, an additional hour of regression testing was added on to the testing. Approximately $15 \%$ of the failures have to be repaired at the fulfillment assembly operation. Once the repairs are made, the server has to go through the 'Inspection 1' operation, followed by the fulfillment test operation. The remaining $5 \%$ of the defects have to be repaired and tested through the fabrication process.

3. Detection of failures at 'Inspection 2': In this stage, approximately $95 \%$ of the defects detected can be repaired in the Inspection 2 operation itself. However, the server has to undergo an hour of regression testing. $4 \%$ of the defects return to the fulfillment assembly operation and follows the process as discussed previously. Only $1 \%$ of the defects return to the fabrication process for repair and rework.

In all the three scenarios discussed above, the proportion of commodities that are scrapped ia also estimated. It was observed that most of the scrapped commodities were identified in the fulfillment test and the 'Inspection 2' processes.

The uniqueness of this research is the use of simulation modeling to estimate the energy consumption in the fulfillment process. The energy consumed per hour in each test cell or workstation $i$, is assigned as $r_{i}$. Based on the time spent in the test cell or workstation, $T_{i}$, the energy $\operatorname{cost}\left(C_{e}\right)$ is calculated as shown in Equation 1.

$$
C_{e}=\sum_{i \in M}\left(c \cdot r_{i} \cdot T_{i}\right)
$$

where $M$ is the set of all test cells and workstations in the system and $c$ is the unit cost. It is possible to estimate the 


\section{Ramakrishnan, Drayer, Tsai, and Srihari}

energy cost by including other factors such as rework/scrapped quantities and cooling efficiency of test cells more accurately. The details of the derivation of this metric is beyond the scope of this paper.

\subsection{Model Validation and Verification}

The model was verified and validated against a different data set that was collected for a period of two quarters. Using the animation feature in the Arena simulation software, the logic was checked to ensure the model was error-free.

Statistical tests, including hypothesis testing and ttests, were conducted to validate the model accuracy. At a confidence level of $95 \%$, it was observed that the results from the model are statistically equivalent to the actual scenario. The key performance measures studied include the total number of orders processed and cycle time. Table 4 presents the summary of the results from the baseline model development. Subsequently, the model and its results were presented to the design and production teams and their inputs were incorporated into the model.

Table 4: Baseline Simulation Model Validation

\begin{tabular}{|l|l|l|l|}
\hline $\begin{array}{l}\text { Performance } \\
\text { Measure }\end{array}$ & $\begin{array}{l}\text { Historical } \\
\text { Data }\end{array}$ & $\begin{array}{l}\text { Baseline } \\
\text { Model }\end{array}$ & $\begin{array}{l}\text { \% Dif- } \\
\text { ference }\end{array}$ \\
\hline Throughput & 342 & 339 & $0.9 \%$ \\
\hline Cycle time & 7.10 days & 7.01 days & $-1.3 \%$ \\
\hline Data for all three product types \\
\hline
\end{tabular}

\subsection{Interface with DFSS Techniques}

The architecture for translating the results from the DFSS analysis into scenarios for the simulation model is discussed here. Based on the output from the QFD and FMEA, the yield model (or any other relevant models) is triggered to determine whether any significant change in the process parameters was detected. Based on the scenarios identified from the DFSS analysis, the user can select the specific scenarios to be studied via the simulation models. Once the scenarios are studied, the outputs are reported to the Excel-based interface and extensive statistical analysis can be conducted through the Output Analyzer. The monitoring module checks for any change in the performance measures over time and reports to the design and process teams in case of an 'out-of-control' situation.

\subsection{Sensitivity Analysis}

In this stage of this research, different scenarios were defined to study various aspects of the fulfillment process in the server manufacturing area. As an illustration, the FPY at fulfillment test are varied to study their impact on the overall manufacturing value added costs. Scenarios included changing the FPY by $\pm 5 \%, \pm 10 \%$ and $-15 \%$. These figures were based on the outcome from the DFSS analysis and feeding the results to the yield models. The results are shown in Figure 5.

The total MVA cost ( $C_{m v a}$ ) can be calculated as follows; energy consumed per hour in each test cell or workstation $i$, is assigned as $r_{i}$. Based on the time spent in the test cell or workstation, $T_{i}$, the energy cost $\left(C_{e}\right)$ is calculated as shown in Equation 1.

$$
C_{\text {mva }}=\sum_{i \in W}\left(c_{i} \cdot r_{i}\right)+\sum_{i \in M}\left(d_{i} \cdot T_{i}\right)+C_{s}+C_{e}
$$

In the equation above, $M$ is the set of all test cells and workstations in the system and $d$ is the incurred cost of a test cell over a year. $W$ represents the total resources required to meet the demands and $c$ is the annual salary of the resource. $C_{S}$ represents the costs due to scrapped commodities, whereas $C_{e}$ represents the energy costs discussed in Equation (1).

These results are then provided to the design teams, especially while introducing design changes to the commodities and sub-assemblies. Moreover, these results provide invaluable information to the capacity planners and schedulers to estimate the required number of test cells and resources required to meet the customer demands based on changes in the FPY.

The sensitivity analysis also helped to study any relationship between the MVA costs and the FPY. It was observed that there exists no linear relationship. However, as a rule of thumb, it could be safely concluded that for an increment in the FPY, the MVA costs decreases by half the rate of change in the FPY.

\section{APPLICATION OF THE FRAMEWORK}

This section presents an application of the proposed DFSSsimulation modeling framework in a server manufacturing environment. To illustrate the applicability of this framework, the FPY in the fulfillment test process of a server manufacturing facility was chosen as the performance metric.

It was observed that there were two main categories of defects that contribute to the FPY - (i) Electrical defects and (ii) Mechanical defects. Upon further analysis, it was concluded that the electrical defects had to be rectified during the product design, whereas the mechanical defects were induced due to poor workmanship, poor tooling design or other design issues. Since a significant portion of defects detected at fulfillment test operation were mechanical defects, the focus of this research was limited to these defects. It was also noted that cables accounted for approximately $75 \%$ of the total mechanical defects. Hence, these commodities were chosen for further analysis.

The design and process teams employed the DFSS techniques - QFD and FMEA - to identify the root causes for the failures and any corrective actions that could be 
taken to reduce, if not eliminate, the occurrences of the cable related defects.

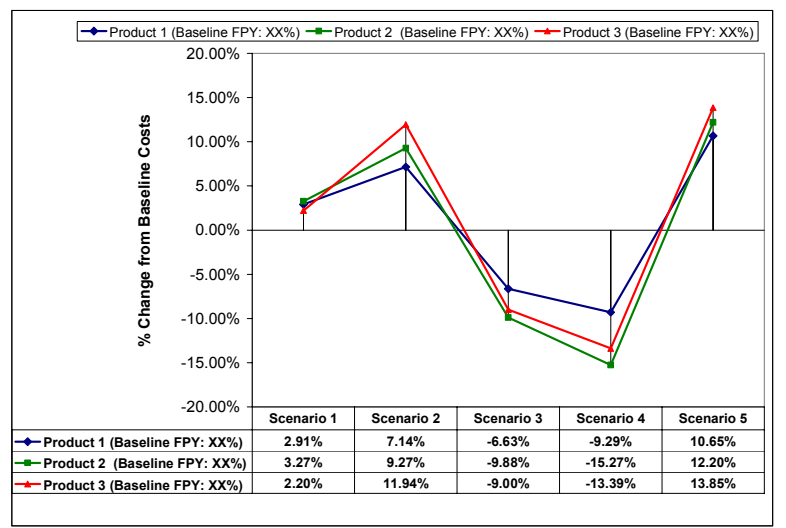

Figure 5: Change in MVA Costs for Scenarios

Additionally, the FMEA showed the process-related and design-related failure modes. Once the corrective actions were identified, the next step involved using designed experiments and simulation modeling to quantify the impact of these actions.

In this example, there were three stages where the defects could be detected, namely Inspection 1, Test and Inspection 2 (as shown in Figure 3). A designed experiment was set-up for these three inspection stages with three levels of detecting defects. The levels were 'High', 'Medium' and 'Low', where each level signifies the probability of capturing more defects at the specific inspection stage. Subsequently, simulation models developed in Section 6 were modified and run for each of experiments and the performance measures were observed and documented. For each scenario, the design costs were also estimated. Table 5 shows the summary of the designed experiment and simulation runs.

Table 5: Results from Designed Experiments

\begin{tabular}{|c|c|c|c|c|c|}
\hline & \multicolumn{3}{|c|}{ Factors and Levels } & \multicolumn{2}{|c|}{ Response Variables } \\
\hline & $\operatorname{lnsp} 1$ & Test & $\operatorname{lnsp} 2$ & Design Costs & MVA Costs \\
\hline \multirow{12}{*}{$\begin{array}{l}\text { Run } 1 \\
\text { Run } 2 \\
\text { Run } 3 \\
\text { Run } 4 \\
\text { Run } 5 \\
\text { Run } 6 \\
\text { Run } 7 \\
\text { Run } 8 \\
\text { Run } 9 \\
\text { Run } 10 \\
\text { Run } 11 \\
\text { Run } 12\end{array}$} & $H$ & $L$ & $L$ & High & $\$ 300,338.11$ \\
\hline & $\bar{H}$ & $L$ & $H$ & Medium & $\$ 452,288.08$ \\
\hline & $H$ & $H$ & $L$ & High & $\$ 352,233.32$ \\
\hline & $H$ & $H$ & $H$ & Medium & $\$ 518,532.20$ \\
\hline & $L$ & $L$ & $L$ & Medium & $\$ 458,077.12$ \\
\hline & $L$ & $H$ & $L$ & Medium & $\$ 429,667.93$ \\
\hline & $L$ & $L$ & $H$ & Low & $\$ 394,653.30$ \\
\hline & $L$ & $H$ & $H$ & Medium & $\$ 542,100.69$ \\
\hline & $M$ & $L$ & $L$ & Low & $\$ 522,342.08$ \\
\hline & $M$ & $L$ & $H$ & High & $\$ 501,742.33$ \\
\hline & $M$ & $H$ & $L$ & High & $\$ 347,046.27$ \\
\hline & $M$ & $H$ & $\bar{H}$ & High & $\$ 532,097.69$ \\
\hline
\end{tabular}

Based on the results from above, it can be concluded that moving most of the defects captured upstream would provide the least MVA costs. However, the design costs involved are high (Run 1). Hence, the design and process teams can decide on the appropriate scenario that is the most feasible based on factors, such as, time required for process/design change and cost differential between scenarios. In this research, Run 1 was chosen as the strategy for improving the FPY. At the time of this writing, it is estimated that the yields would improve by approximately $5 \%$ by implementing the corrective actions identified by the FMEA.

This case study illustrates the seamless functioning of the integrated DFSS-simulation modeling framework in a server manufacturing environment. It can be seen that these two techniques are complementary in nature.

\section{CONCLUSIONS}

This research presents the application of DFSS techniques and simulation modeling in a server manufacturing environment. These environments are characterized by long test cycle times, constant engineering design changes and low first pass yields. Additionally, a large number of factors influence the manufacturing process - a source for variation and randomness.

In such environments, deterministic decision making can not provide an effective and accurate solution. Using simulation modeling, the randomness in the process can be accounted for and is highly effective to predict and improve processes and product designs. Additionally, DFSS techniques are extremely useful for improving the product and process designs using methods such as QFD and FMEA. The integrated simulation modeling - DFSS techniques used in this research is a major contribution of this research. The applicability of this framework was demonstrated through an illustrative case study in a server manufacturing environment.

\section{REFERENCES}

Benjaafar, S., and M. ElHafsi 2006. Production and inventory control of a single product assemble to order system with multiple customer classes. Management Science 52(12):1896-1912.

Cheng, F., M. Ettl., Y. Lu, and D.D. Yao. 2005. A twostage push-pull production planning model. Working paper, IBM T.J.Watson Research Center: 1-28, Available via <http://www.kellogg.northwestern.edu /MSOM2005/papers/Ettl.pdf> [accessed January 3, 2008].

Chen, Y., J. Fowler, T. Wu, T. Callarman, E. Ambrose, and V. Hargaden. 2006. An adaptive distributed simulation framework for a server fulfillment supply chain. In Proceedings of IEEE International Conference on Automation Science and Engineering, 649-655.

Cao, H., F. Cheng, H. Xi, M. Ettl, S. Buckley, and C. Rodriguez. 2003. A simulation based tool for inventory analysis in a server computer manufacturing environ- 
ment. In Proceedings of the 2003 Winter Simulation Conference, ed. S. Chick, P. J. Sánchez, D. Ferrin, and D. J. Morrice, 1313-1318. Piscataway, New Jersey: Institute of Electrical and Electronics Engineers, Inc.

Drayer, C.M., L. Cai, E. Vellone, and K. Okonji. 2008. A simulation based approach for resource planning for a service upgrade unit in a high-end server manufacturing environment. In Proceedings of the 2008 IIE Annual Conference and Exposition, 685-690.

Eldabi, T., and T. Young. 2007. Towards a framework for healthcare simulation. In Proceedings of the 2007 Winter Simulation Conference, ed. S. G. Henderson, B. Biller, M.-H. Hsieh, J. Shortle, J. D. Tew, and R. R. Barton, 1454-1460. Piscataway, New Jersey: Institute of Electrical and Electronics Engineers, Inc.

Ferrin, D.M., M. Miller, and D. Muthler. 2005. Lean sigma and simulation, so what's the correlation? v2. In Proceedings of the 2005 Winter Simulation Conference, ed. M. E. Kuhl, N. M. Steiger, F. B. Armstrong, and J. A. Joines, 2011-2015. Piscataway, New Jersey: Institute of Electrical and Electronics Engineers, Inc.

Kuhn, W. 2006. Digital factory - Simulation enhancing the product and production engineering process. In Proceedings of the 2006 Winter Simulation Conference, ed. L. F. Perrone, F. P. Wieland, J. Liu, B. G. Lawson, D. M. Nicol, and R. M. Fujimoto, 1899-1906. Piscataway, New Jersey: Institute of Electrical and Electronics Engineers, Inc.

Luce, K., L. Trepanier, F. Ciochetto, and L. Goldman. 2005. Simulation and optimization as effective DFSS tools. In Proceedings of the 2005 Winter Simulation Conference, ed. M. E. Kuhl, N. M. Steiger, F. B. Armstrong, and J. A. Joines, 1393-1400. Piscataway, New Jersey: Institute of Electrical and Electronics Engineers, Inc.

Mead, D.J., S. Kumar, and A. Houshyar. 2006. Financial analysis of a theoretical lean manufacturing implementation using hybrid simulation modeling. Journal of Manufacturing Systems 25(2):1-11.

Rivera, A., and J. Markovich. 2001. Use of six sigma to optimize cordis sales administration and order and revenue management process. In Proceedings of the 2001 Winter Simulation Conference, ed. B. A. Peters, J. S. Smith, D. J. Medeiros, and M. W. Rohrer, 12521258. Piscataway, New Jersey: Institute of Electrical and Electronics Engineers, Inc.

Revetria, R., and F. Tonelli. 2007. Reflective simulation for on-line workload planning and control. In Proceedings of the 2007 Winter Simulation Conference, ed. S. G. Henderson, B. Biller, M.-H. Hsieh, J. Shortle, J. D.
Tew, and R. R. Barton, 1814-1819. Piscataway, New Jersey: Institute of Electrical and Electronics Engineers, Inc.

Standridge, C.R., and J.H. Marvel. 2006. Why lean needs simulation. In Proceedings of the 2006 Winter Simulation Conference, ed. L. F. Perrone, F. P. Wieland, J. Liu, B. G. Lawson, D. M. Nicol, and R. M. Fujimoto, 1907-1913. Piscataway, New Jersey: Institute of Electrical and Electronics Engineers, Inc.

van-der Zee, D-J., and J. Slomp. 2005. Simulation and gaming as a support tool for lean manufacturing systems - A case study from the industry. In Proceedings of the 2005 Winter Simulation Conference, ed. M. E. Kuhl, N. M. Steiger, F. B. Armstrong, and J. A. Joines, 2304-2313. Piscataway, New Jersey: Institute of Electrical and Electronics Engineers, Inc.

\section{AUTHOR BIOGRAPHIES}

SREEKANTH RAMAKRISHNAN is a Learning Consultant with IBM Corporation. He completed his M.S and Ph.D. in Industrial and Systems Engineering from Binghamton University, State University of New York, Binghamton, NY. He is a member of IIE and SMTA. His research interests include discrete event simulation modeling, lean manufacturing and information systems.

CHRISTIANA M. DRAYER is an Industrial Engineer in the Integrated Supply Chain (Engineering) operations in the High-end Server manufacturing line at IBM Corporation, Poughkeepsie, NY. She received a master's degree in Industrial Engineering from The Pennsylvania State University, State College, PA, in 2007. She is a member of SWE and IIE.

PEI-FANG TSAI is a Research Assistant Professor at the Watson Institute for Systems Excellence at Binghamton University, State University of New York, Binghamton, NY. She received her Ph.D. in Industrial Engineering from Virginia Polytechnic Institute in 2006.

KRISHNASWAMI SRIHARI is a Distinguished Professor and the Chair of the Department of Systems Science and Industrial Engineering at Binghamton University, State University of New York, Binghamton, NY. He is also the Director of the Watson Institute for Systems Excellence. He received his Ph.D. in Industrial Engineering from Virginia Polytechnic Institute in 1988 . His personal webpage is $<$ http: / / emrs.binghamton. edu/hari> 